\title{
Efficacy of Bronchial Wash Cytology and its Correlation with Histopathology in Diagnosis of Lung Carcinoma in a Tertiary Care Hospital
}

\author{
Shilpa Tomar ${ }^{1 *}$, Brijesh Thakur ${ }^{2}$, Krishna Dubey ${ }^{3}$ and Priyanka Gulati ${ }^{4}$ \\ 'G Department of Pathology, GS Medical College, Pilkhuwa, Hapur \\ ${ }^{2}$ SGRRIM \& HS, Dehradun \\ ${ }^{3}$ Department of Pathology, GMC Medical College, Kota \\ ${ }^{4}$ Department of Pathology, GS Medical College, Pilkhuwa, Hapur
}

\begin{abstract}
Introduction: Cytological evaluation is an important, usually initial diagnostic modality in patients with suspected malignant lung masses. Bronchoscopic washing, bronchoalveolar lavage, bronchial brushing and fine needle aspirations may complement tissue biopsies in the diagnosis of lung cancer. This study was undertaken to compare the efficacy of bronchial wash cytology and to correlate it with histopathology in diagnosis of suspected cases of lung cancer at a tertiary care hospital.

Material and Methods: Bronchial washings and bronchial biopsy were collected from total 60 clinically suspected cases of carcinoma lung. Bronchial washing smears were stained with MGG and H\&E stain and were categorized as unequivocally positive / unequivocally negative for malignancy and atypical (equivocal for diagnosis). Biopsy sections were examined for histopathological diagnosis.

Results: Cytomorphologically, 30 cases were reported as positive for malignancy, 28 cases were negative for malignancy and 02 cases were atypical. On histopathology, lung carcinoma was diagnosed in 48 patients out of them 35 cases were of squamous cell carcinoma, 7 cases were of small cell carcinoma and 6 were of large cell carcinoma.
\end{abstract}

Conclusion: Maximum diagnostic yield can be obtained by combining biopsy with cytological procedures of washing rather alone.

Keywords: Bronchial-Washing, Carcinoma, Lung, Sensitivity, Specificity

\section{Introduction}

Pulmonary lesions are mostly caused by infections such as tuberculosis/ pneumonia and lung cancer or secondaries. It usually appears as white, round shadows on x-rays or CT scan. Histopathology remains the gold standard in diagnosis of these diseases. ${ }^{[1]}$ In India, GLOBOCAN 2012 reported an incidence of lung cancer as 75,275 in all age groups and both genders. ${ }^{[2]}$ The use of cytological methods in diagnosis of malignant as well as non-malignant lesions of respiratory tract has been generally acclaimed as one of its most successful applications. ${ }^{[3]}$ Bronchoscopic washing, bronchoalveolar lavage, bronchial brushing and fine needle aspirations may complement tissue biopsies in the diagnosis of lung cancer. ${ }^{[4]}$

Bronchial washing has proven to be an economical, safe, and cost-effective technique, particularly in cases with highly vascularized lesions or small cell carcinomas where crush artifacts are relatively common. ${ }^{[5]}$ In addition, cell samples obtained via bronchial washing can also be cultivated for micro-biological analysis. ${ }^{[6]}$ Therefore this study was undertaken to compare the efficacy of bronchial wash cytology and to correlate it with histopathology in diagnosis of suspected cases of lung cancer at a tertiary care hospital.

\section{Material and Methods}

Total 60 clinically suspected cases of carcinoma lung were studied over a period of two years. Approval of the study was taken from Institutional Ethical Committee. Detailed relevant clinical, radiological and routine investigation findings were recorded on predesigned proforma. Past and present history of any anti-tubercular treatment taken was recorded in every patient. Complete general physical examination, examination of respiratory system and other systems was performed with special reference to metastasis and/or paraneoplastic syndromes.

CT scan was done in maximum possible cases for proper evaluation of pulmonary lesions i.e. characterizing tissue densities for providing accurate size assessment of lesion, presence and type of calcification as well as detecting mediastinal lymphadenopathy. All centrally located lesions in suspected cases of carcinoma lung were included. Exclusion criteria include peripherally situated lung lesions, cases of carcinoma metastasizing to the lung and inadequate tissue for opinion. 
Bronchial washings and bronchial biopsy were collected from tracheo-bronchial lesions suspected of carcinoma lung. All samples were taken after taking signed informed consent explaining the potential hazards of bronchoscopy and topical anesthesia. The tracheobronchial tree including all the segmental and subsegmental bronchi was inspected for any visible lesion. Biopsy was taken from visible growth or lesion over the bronchus and fixed in $10 \%$ formalin. 5-10 ml normal saline was put through inner channel and washings were collected by suctioning into a trap which was connected to the bronchoscope. Biopsy as well as bronchial washings was sent to pathology department for further analysis.

Bronchial washing samples were centrifuged and air-dried smears were stained by May-Grunwald Giemsa(MGG). Wet fixed (95\% alcohol) smears were stained by Hematoxylin $\&$ Eosin (H\&E). On the basis of cytomorphology, bronchial washings results were categorized as unequivocally positive / unequivocally negative for malignancy and atypical (equivocal for diagnosis). Standard techniques for biopsy processing and preparation of tissue sections were followed. H\&E-stained sections were examined for histopathological diagnosis. All the data was recorded and analyzed.

\section{Results}

In the present study, age range of the selected patients varied from $36-80$ years. $79.2 \%$ cases were in the age range of 50-80 years and $20.8 \%$ cases were less than 50 years of age group. Mean age of patients was 59.08 years. 53 male and 7 female patients were included. In our study, the major constitutional symptom was chest pain followed by anorexia and malaise. Most common respiratory symptom was chest pain, followed by shortness of breath, cough with or without expectoration and hemoptysis. The frequent physical sign was anemia and clubbing followed by cervical lymphadenopathy and superior vena cava syndrome. Bronchoscopy revealed obstruction and narrowing of bronchi in most of the cases, followed by cauliflower like irregular growth and presence of black necrotic patch.

Out of 60 bronchial washing samples, 30 cases were reported as positive for malignancy (fig $1 \mathrm{a}, \mathrm{b} \& \mathrm{~d}$ ), 28 cases were negative for malignancy and 02 cases were atypical. On histopathology, lung carcinoma was diagnosed in 48 patients, out of which $43(85.58 \%)$ were males and 05 $(10.41 \%)$ were females with a male to female ratio of 8.6:1. In our experience, 38 cases $(79.16 \%)$ of lung carcinoma were smokers and 10 cases $(20.83 \%)$ were non smoker. On sub-typing, 41 cases $(85.41 \%)$ were of non-small cell carcinoma while remaining 7 cases $(14.58 \%)$ were of small cell carcinoma (fig 1 c \& e). Out of 41 cases, $35(85.36 \%)$ cases were of squamous cell carcinoma and $6(14.63 \%)$ were of large cell carcinoma.

09 biopsy specimens were found to be negative for malignancy while 03 cases revealed dysplastic change but not definitive for diagnosis of malignancy. In dysplastic cases, close follow up was advised. Three dysplastic cases on histopathology and two atypical cases on cytology were excluded from the statistical analysis of data. The sensitivity and specificity of bronchial washing samples were found to be $62.5 \%$ and $100 \%$ respectively.

Table 1: Results of Bronchial Washings and Biopsy $(n=60)$.

\begin{tabular}{|l|l|l|}
\hline \multirow{2}{*}{ Results } & Number of Cases (\%) \\
\cline { 2 - 3 } & Bronchial Washings & Biopsy \\
\hline Positive for Malignancy & $30(50 \%)$ & $48(80 \%)$ \\
\hline Negative for Malignancy & $28(46.67 \%)$ & $9(15 \%)$ \\
\hline Atypical/ dysplastic change & $02(3.33 \%)$ & $3(5 \%)$ \\
\hline Total & $\mathbf{6 0 ( 1 0 0 \% )}$ & $\mathbf{6 0 ( 1 0 0 \% )}$ \\
\hline
\end{tabular}

Table 2: Histological typing of Carcinoma lung cases $(n=48)$.

\begin{tabular}{|l|l|l|}
\hline Histological diagnosis & No. of Cases & Percentage (\%) \\
\hline 1. Squamous cell carcinoma & & \\
$\quad$ Well differentiated & 01 & 2.08 \\
$\quad$ Moderately differentiated & 30 & 62.50 \\
Poorly differentiated & 04 & 8.33 \\
\hline 2. Large cell carcinoma & 06 & 12.50 \\
\hline 3. Adenocarcinoma & 00 & 00 \\
\hline 4. Small Cell Carcinoma & 07 & 14.59 \\
\hline Total & $\mathbf{4 8}$ & $\mathbf{1 0 0}$ \\
\hline
\end{tabular}


Table 3: Correlation of final histopathology with cytology of bronchial washing.

\begin{tabular}{|l|l|l|l|}
\hline \multirow{2}{*}{$\begin{array}{l}\text { Cytological diagnosis } \\
\text { (bronchial washing) }\end{array}$} & Histopathological diagnosis & \multirow{2}{*}{ Total } \\
\cline { 2 - 3 } & Malignant & Non-malignant & \\
\hline Positive for Malignancy & 30 & 00 & 30 \\
\hline Negative for malignancy & 18 & 07 & 25 \\
\hline Total & $\mathbf{4 8}$ & $\mathbf{0 7}$ & $\mathbf{5 5}$ \\
\hline
\end{tabular}

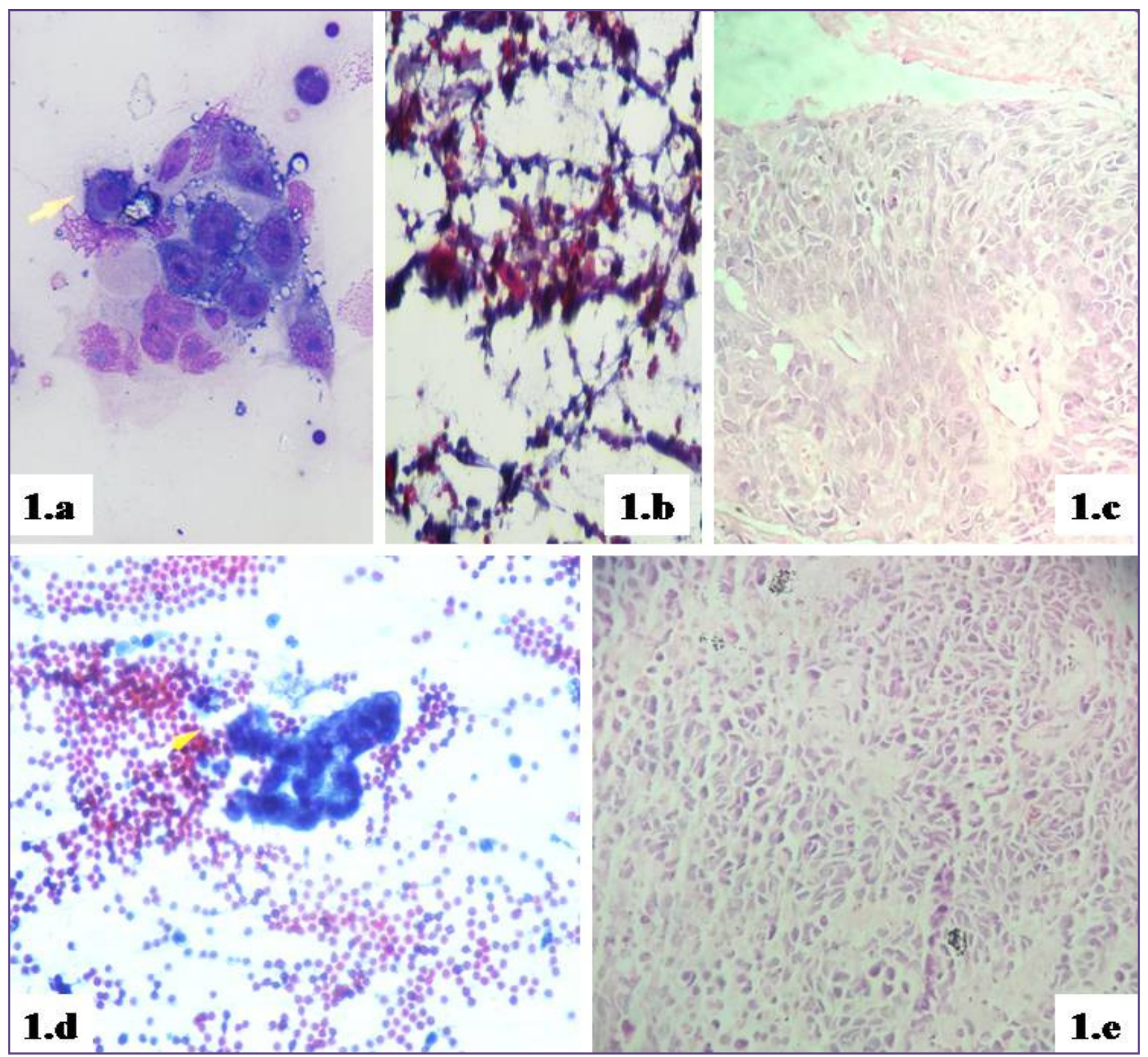

Fig. 1: a. Smear showing cluster of large atypical cells; suggestive of malignancy, bronchial washing (MGG,400X) b. Smear showing a few keratinized atypical squamous cells; suggestive of well-differentiated squamous cell carcinoma, bronchial washing(PAP,100X), c. Histomorphological features suggestive of squamous cell carcinoma, bronchial biopsy(H\&E, 400X), d. Smear showing cluster of small atypical cells with high N/C ratio \& dense nuclei; suggestive of small cell carcinoma, bronchial washing (MGG,400X), e. Histomorphological features suggestive of small cell carcinoma, bronchial biopsy(H\&E,400X) 


\section{Discussion}

Lung cancer is the most common malignant disease worldwide with 9,00,000 new cases each year in males and $3,30,000$ in women. ${ }^{[7]}$ National Cancer registry program by Indian council of medical research in 3 cities (Bhopal, Delhi and Mumbai) showed lung as the commonest site for cancer among males. ${ }^{[8]}$ Male to female ratio of 8.6:1 in lung carcinoma cases was observed in our study; suggesting that the disease is more common in males which was consistent with previous studies by various authors like $4.9: 1$ by Wig et $\mathrm{al}^{9}, 7.9: 1$ by Rajasekaran et $\mathrm{l}^{10}, 6: 1$ by Arora et al ${ }^{1 \mathrm{q}}, 8: 1$ by Ahmed et $\mathrm{al}^{12}$, and 7.5:1 by Gaur et a $1 .{ }^{13}$ The incidence of lung cancer has been reported to be low before the age of 40 years in both males and females and after that it increases up to the age of 70 years. ${ }^{[7]}$ Mean age of patients was 59.08, which was in concordance with the mean age as seen by Ahmad et $\mathrm{al}^{12}$, Gaur et $\mathrm{al}^{13}$, Buccheri et $\mathrm{al}^{14}$ and not correlated to the mean age $(<50$ years) as observed by Jha et al. ${ }^{[15]}$

Incidence of smoking history $(79.16 \%$ cases) in lung carcinoma patients correlated well with Hecht et $\mathrm{al}^{16}$ and Ochsner et $\mathrm{al}^{17}$ where $82-90 \%$ cases had a history of smoking. The smoker to non smoker ratio was 3.8:1 which was slightly higher than $2.7: 1$ given by Jindal et al. ${ }^{[18]}$

In this study, non-small cell carcinoma (85.41\%) predominantly of squamous cell carcinoma subtype was main diagnosis on histopathology. According to literature searched also, non-small cell cancers are usually found in around $80 \%$ of the total lung cancers and small cell cancers, around $16 \%$ of carcinoma lung. No case of adenocarcinoma was noticed in this study. However, there was a selection bias because only centrally located and endoscopically visible tumors were included. Ahmed et $\mathrm{al}^{12}$ also reported that squamous cell carcinoma is the most frequent lung cancer, being present in $68.3 \%$, small cell carcinoma in $21.9 \%$ and adenocarcinoma in $4.9 \%$.

The histologic subtype pattern varies from different studies in India. According to Vishwanathan et $\mathrm{al}^{19}{ }^{19}$, the predominant cell type was squamous cell carcinoma $(50.5 \%)$, followed by adenocarcinoma (26.4\%) and unclassified (21\%) among 95 patients. Similarly, squamous cell carcinoma was predominant in studies by Buccheri et $\mathrm{al}^{14}$, Jindal et al, ${ }^{18}$ Arora et al. $^{11}$ and Bhattacharya et $\mathrm{al}^{20}$. However, a changing trend in histopathological profile of lung cancer patients is being observed worldwide and adenocarcinoma has replaced squamous cell carcinoma as the predominant subtype in various studies like conducted by Kumar et al. ${ }^{21}$, Piplani et al, ${ }^{22}$ and Jerse et $\mathrm{al}^{23}$.

In the present study, bronchial washings with biopsy gave 30 true positives and 07 true negatives, 18 cases were false negative and no false positive case was detected. Exact concordance between histopathology and bronchial wash cytology was present in 30 of 48 cases $(62.5 \%)$. The diagnosis by bronchial washing mainly relies on the cells that have been exfoliated in the bronchial epithelium. The adequacy of washing samples depends on several factors such as the site and size of lesion, degree of differentiation and stage of the disease, preservation of the morphology of the cytological material obtained and the skill of the pulmonologist who retrieves the samples. The poorly differentiated tumors are less cohesive than the well differentiated ones and thus exfoliate larger number of cells in the bronchial cavity. Secondly, while these exfoliated cells are lying in the bronchus, they start developing degenerative changes, thus progressively losing their morphological details which are important in differentiating them from non-malignant cells shed off by the normal bronchial epithelial lining. The presence of inflammation, necrotic debris or crushing artifact can affect the overall yield and diagnostic efficacy of bronchial washing samples.

Variability in the sensitivity and specificity of pulmonary cytology in diagnosis of both benign and malignant lesions is seen across various studies. In our study, sensitivity, specificity and accuracy of bronchial washing samples were $62.5 \%$ and $100 \%$ respectively. Truong et al 24 reported sensitivity of $66 \%$, while Tuladhar et $\mathrm{al}^{25}$ observed sensitivity as low as $17.4 \%$. Solomon et $\mathrm{al}^{26}$ found bronchial washing to be of minimal value in the diagnosis of lung malignancy. Lam et a $1^{27}$ reported a sensitivity of 76 $\%$ in endobronchially visible lung cancer and $52 \%$ for non visible cancer.

A study by Mufti et al showed that combined use of bronchial wash and bronchial brush increased the sensitivity to $90.6 \%$ and specificity to $75 \%{ }^{[28]}$ Ahmed et $\mathrm{al}^{12}$ observed values as high as $80.5 \%$ for sensitivity, $96.6 \%$ for specificity and $87.3 \%$ for accuracy. Gaur et a $1^{13}$ have reported sensitivity, specificity and accuracy of Bronchial Washing samples as $39.4 \%, 89.6 \%$ and $71.4 \%$ respectively. Rao et al found sensitivity and specificity of $52.63 \%$ and $80 \%$ which is slightly less than our study. ${ }^{[29]}$

\section{Conclusion}

Cytological analysis of bronchial washings is of some value as it may reveal an early diagnosis in about $2 / 3^{\text {rd }}$ of the patients and a suspicious cytology may alert the pathologist to review histopathology. However, by itself, it may not be having enough sensitivity and simultaneously taken biopsy is additive to the diagnosis. Maximum diagnostic yield can be obtained by combining biopsy with cytological procedures of washing rather alone, although bronchial washing samples become more significant when 
biopsy is contraindicated. Rapid onsite evaluation for sample adequacy and wider use of ancillary techniques like immunocytochemistry may help in increasing its diagnostic accuracy.

\section{References}

1. Myron R. Melamed, Leopard G Koss.In:Koss' cytopathology.5th ed. Philadelphia: Lippincott Williams \& Wilkins; 2009.

2. Ferlay J, Soerjomataram I, Ervik M. GLOBOCAN 2012 vl.0, Cancer Incidence and mortality worldwide: IARC Cancer Base No 11. International agency for research on cancer. GLOBOCAN 2013;2012VL.0.

3. Johnston WW, Elson CE. Comprehensive cytopathology.2nd ed. Philadelphia: W.B. Saunders Company;1997.

4. Young JA. Techniques in Pulmonary cytopathology. J Clin Pathol. 1993;46(7):589-95.

5. Mazzone P, Jain P, Arroliga AC, Matthay RA. Bronchoscopy and needle biopsy techniques for diagnosis and staging of lung cancer. Clin Chest Med. 2002;23(1):137-58.

6. Villara AF, Gonzálezb A, Leiroa V, Represasa C, Botanaa MI. Effect of Different Bronchial Washing Sequences on Diagnostic Yield in Endoscopically Visible Lung Bronconeumol. 2006; 42(6):278-82. DOI:10.1016/S15792129(06)60143-2.

7. Stewart BW, Kleihues P. World cancer report (World health organisation press, Geneva, 2003).

8. Noronha V, Pinninti R, Patil VM, Joshi A, Prabhash K. Lung cancer in the Indian subcontinent. South Asian J Cancer. 2016;5:95.

9. Wig KL, Lazaro EJ, Gadekar NG, Guleria JS. Bronchogenic carcinoma (clinical features and diagnosis). Indian J Chest Dis. 1961;3:209-18.

10. Rajasekaran S, Manickam TG, Vasanthan PJ. Pattern of lung cancer- A Madras study. Lung India. 1993;11:7-11.

11. Arora KV, Navjeevan S, Sujata C, Arati B. Significance of cytologic criteria in distinguishing small cell from non small cell carcinoma of the lung. Acta Cytol. 2003;47:216-20.

12. Ahmad M, Afzal S, Saeed W et al. Efficacy of Bronchial Wash Cytology and its correlation with Biopsy in Lung Tumours. Journal of Pakistan medical association. 2004;54(1):13-6.

13. Gaur DS, Thapliyal NC, Kishore S, Pathak VP. Efficacy of bronchoalveolar lavage and bronchial brush cytology in diagnosing lung cancers. J Cytol. 2007;24(1):73-7.

14. Buccheri G, Barberis $P$ and Delfino MS. Diagnostic, morphologic, and histopathologic correlates in bronchogenic carcinoma. A review of 1,045 bronchoscopic examinations. Chest. 1991;99;809-14.
15. Jha VK, Roy DC, Ravindran P. Bronchogenic Carcinoma: A clinicopathologic study. Ind I Chest Dis. 1972;14:78-85.

16. Hecht SS. Tobacco smoke, carcinogens and lung cancer. J Natl. Cancer Inst. 1999;91(14):1194-1210.

17. Ochsner A. Bronchogenic carcinoma. A largely preventable lesion assuming epidemic proportions. Chest. 1971;59(4):358-9.

18. Jindal SK, Behara D. Clinical spectrum of pulmonary lung cancer; Review of Chandigarh experience of 10 years. Lung India. 1990;8:94-8.

19. Viswanathan R, Gupta S, lyer PVK. Incidence of primary lung cancer in India. Thorax. 1962;17(1):73-6.

20. Bhattacharya SK, Mandal A, Deoghuria D, Agrawal A, Alok GG, Dey SK. Clinicopathological profile of lung cancer in a tertiary medical centre in India: Analysis of 266 cases. Journal of Dentistry and Oral hygiene. 2011;3:30-3.

21. Kumar M, Sharma DK, Garg M, Jain P. Clinicopathological profile of lung cancer- changing trends in India. Int J Resp Med. 2016;5:57-62.

22. Piplani S, Mannan R, Lalit M, Manjari M, Bhasin TS, Bawa J. Cytologic-radiologic correlation using transthoracic CTguided FNA for lung and mediastinal masses: our experience. Analytical Cellular Pathology. 2014;2014(34):1-6.

23. Jerse MJ, Tercelj M. Contributions of cytology examination and methods in lung cancer diagnosis. Radiol. 2006;40:S7785.

24. Truong LD, Underwood RD, Greenberg SD, McLarty JW. Diagnosis and typing of lung carcinomas by cytopathologic methods. A review of 108 cases. Acta Cytol. 1985;29:379. 84.

25. Tuladhar A, Panth R, Joshi AR. Comparative analysis of cytohistologic techniques in diagnoses of lung lesions. Journal of Pathology of Nepal. 2011;1:126-30.

26. Solomon DA, Solliday NH, Gracey DR. Cytology in fibreoptic bronchoscopy. Chest.1974;65(6):616-9.

27. Lam WK, So SY, Hsu C, Yu DY. Fiberoptic bronchoscopy in the diagnosis of bronchial cancer: Comparison of washings, brushings biopsies in central and peripheral tumors. Clin Oncol. 1983;9(1):35-42.

28. Mufti ST, Mokhtar GA. Diagnostic value of bronchial wash, bronchial brushing, fine needle aspiration cytology versus combined bronchial wash and bronchial brushing in the diagnosis of primary lung carcinoma at a tertiary care hospital. Biomedical Research. 2015;26:777-84.

29. Rao S, Lal A, Barathi G, Dhanasekar T, Duvura P. Bronchial wash cytology: A study on morphology and morphometry. J Cytol. 2014;31:63.

*Corresponding author:

Dr Shilpa Tomar, GS Medical College, Pilkhuwa, Hapur

Phone: +91 9717716747

Email: drs.tomar03@gmail.com

$\begin{array}{ll}\text { Date of Submission } & : 31 / 08 / 2020 \\ \text { Date of Final Revision } & : 03 / 02 / 2021 \\ \text { Date of Acceptance } & : 12 / 02 / 2021 \\ \text { Date of Publication } & : 28 / 02 / 2021\end{array}$

Financial or other Competing Interests: None. 